\title{
The Impact of Task Complexity on L2 Learners' Written Narratives
}

\author{
Massoud Rahimpour (Corresponding author) \\ The University of Tabriz \& The University of Queensland \\ Tel: 98-339-2165Ｅ-mail: rahimpour2003@yahoo.com \\ Pakhshan Hosseini \\ The University of Tabriz \\ Tel: 98-411-339-2165Ｅ-mail:pakhshanhosseini@yahoo.com
}

\begin{abstract}
This main purpose of this paper is to investigate the impact of task complexity on L2 learners' written narratives. It is argued that L2 learners' written performance is influenced by the complexity of task regarding accuracy, fluency, and complexity.

52 Iranian English learners were selected as the participants of the study. They were asked to write two narratives based on two different picture stories. First, they performed the here-and-now task (present tense and context-supported) and then, they performed the there-and-then task (past tense and context-unsupported). Next, the written narratives were coded to measure the accuracy, fluency, and complexity.

The results of this study demonstrated that cognitively more demanding tasks were more fluent and no significant effects on written narratives were observed on measures of accuracy and complexity.
\end{abstract}

Keywords: Task complexity, Written narratives, Accuracy, Fluency, Complexity

\section{Introduction}

Task is viewed as a pedagogic tool for the language teacher and a central unit for syllabus design and research (Williams \& Burden, 1997). Therefore, due to importance of task, many studies have been done to investigate different aspects of it. A central issue in TBLT involves the impact of task complexity on L2 learners' performance. The majority of previous empirical studies have examined the effects of task complexity on L2 learners' oral task performance (Robinson, 1995, 2001, 2007; Rahimpour, 1997, 1999, 2007; Foster \& Skehan, 1999; Skehan \& Foster, 1999; Ortega, 1999; Yuan \& Ellis, 2003; Gilabert, 2007; Ishikawa, 2008; Kim, 2009) but relatively few studies (Ishikawa, 2006; Kuiken \& Vedder, 2007; Kuiken \& Vedder, 2008) have investigated the role of task complexity in written performance. It implies that less attention has been paid to the effects of task complexity on written performance.

\section{Literature review}

According to Kuiken \& Vedder (2007), there are four major approaches in task-based research: 1) a psychological, interactional approach; 2) a sociocultural approach; 3) a structure-focused approach; and 4) a cognitive, information-theoretic approach. Among these approaches, Robinson $(2001,2003,2005)$ and Skehan $\&$ Foster $(1999,2001)$ consider cognitive approach in their studies where the focus is on the cognitive processes used by learners during task completion. They investigate how task complexity influences the L2 learners' performance.

Robinson (2001) proposed a framework, Triadic Componential Framework, which distinguishes three task components: task complexity, task conditions, and task difficulty (see Table 1). This framework is based on cognition hypothesis. As Robinson \& Gilabert (2007) assert, the main pedagogic claim of cognition hypothesis is that pedagogic tasks should be designed and sequenced on the basis of increases in their cognitive complexity. In other words, Robinson \& Gilabert (2007) declare that the information about the effect of task complexity on language performance can be used to guide decision-making about sequencing tasks in syllabus design.

Insert Table 1 Here

Robinson (2001, p.29) defines task complexity as "the result of attentional, memory, reasoning, and other information processing demands imposed by the structure of the task on the language learner." Therefore, as Ishikawa (2006) declares, task complexity is considered as cognitive in nature and it is manipulable by teachers and syllabus designers before task performance. Robinson (2005) believes that information about the effect of 
task complexity on language performance is helpful in designing tasks from simple to complex, in a way that they gradually approximate real world tasks. Robinson $(2001,2003,2005)$ also makes a distinction between two categories of the dimensions of task complexity: resource-directing dimensions including few/many elements, here-and-now /there-and-then, with/without reasoning demands and resource-dispersing dimensions including with/without planning, single/dual task, with/without prior knowledge. Robinson $(2001,2003,2005)$ believes that increasing task complexity along resource-directing dimensions affects accuracy and complexity positively and fluency negatively. However, he states that increasing task complexity along resource-dispersing dimensions causes problems for L2 learners not to access their current L2 knowledge. In this framework, in addition, task difficulty refers to the learners' perceptions of difficulty. The factors affecting perceptions of difficulty such as proficiency and anxiety are difficult to identify before task performance. Therefore, they cannot be used as a basis for decision-making in sequencing tasks. Task conditions, as well, include participation factors and participant factors.

On the other hand, Skehan $(1996,1998)$ takes into account three areas that together determine task complexity: 1) code complexity that includes linguistic and lexical complexity, 2) cognitive complexity that consists of cognitive processing and cognitive familiarity, and 3) communicative stress including time pressure, modality, scale, stakes, and control. Skehan (1998) describes task complexity as consisting of cognitive factors that can be manipulated during task design to obtain the desired elicitation of learner language. Skehan $(1996,1998)$ tries to separate learner's general goal, becoming more native-like in one's performance, into three specific areas: accuracy, fluency, and complexity. Skehan (1996) proposes a trade-off relationship that operates between these three aspects of speaker production in a particular task. It means that the learner cannot give full attention to these three aspects of language production simultaneously. Therefore, according to him, some tasks may lead learners to prioritize fluency, others to prioritize complexity or accuracy of production. Skehan and Foster (2001), proposing Limited Attentional Capacity Model, believe that different task aspects and conditions of task performance can affect learners' attention to the accuracy, fluency or complexity of their language and this involves a trade-off on these dimensions. In line with the discussion above, the following research question and research hypothesis were formulated.

\section{Method}

\subsection{Research question}

What is the effect of increasing task complexity (here-and-now task versus there-and-then task) on the L2 learners' written performance regarding accuracy, fluency, and complexity?

\subsection{Research hypothesis}

Increasing task complexity has significant effect on L2 learners' written performance regarding accuracy, fluency, and complexity.

\subsection{Participants}

The participants of this study were 52 Iranian learners of English, both males and females. They were learning English as a foreign language at an English institute in Mahabad. All the participants had Kurdish as their mother tongue. The age range was between 14 and 22. All the participants performed two tasks: here-and now (HN) task and there-and-then (TT) task.

\subsection{Instruments}

In this study two picture stories were chosen as instruments for data collection. In order to avoid the effect of topical knowledge on L2 learners' writing, the picture stories were chosen from every day subjects. In order to prevent the practice effect, in addition, two different picture stories were chosen. The picture story applied in here-and-now task (simple task) was adopted from Teaching the Spoken Language by Brown \& Yule (1983) (Appendix A). The picture story for there-and-then task (complex task) was adopted from Referential Communication Tasks by Yule (1997) (Appendix B).

\subsection{Variables of the study}

Independent variable: Task complexity at two levels (simple task vs. complex task)

In this study, the here-and-now task that required present tense (now) and context supported references (here) was simple task and the there-and-then task that required past tense (then) and context unsupported references (there) was complex task.

Dependent variable: written performance at three levels of accuracy, fluency and complexity. 
In this study, the participants' written performance was evaluated in terms of accuracy, fluency, and complexity based on the measures that will be discussed below.

\subsection{Dependent variable measurements}

In this study, the participants' written performance was evaluated in terms of accuracy by calculating the number of error-free T-units per T-units (Arent, 2003; Storch, 2009). Hunt (1966, p.735), defines T-unit as "one main clause plus whatever subordinate clauses happen to be attached to or embedded within it" (Cited in Storch 2009, p.107). Those T-units that contained no grammatical, lexical or spelling errors were counted as error-free T-units.

Regarding fluency a measure of words per T-units was adopted (Arent, 2003; Ishikawa, 2006). It means that the total number of words in the narrative was divided by the number of T-units in the narrative.

In order to measure complexity, a measure of S-nodes per T-units was employed (Robinson, 1995; Rahimpour, 1997; Gilabert, 2004; Ishikawa, 2006). In this case, the number of sentence nodes, indicated by tensed and untensed verbs, in a narrative was divided by the total number of T-units in the narrative.

\subsection{Procedure}

Before the experiment, the participants were told that the tasks they would complete were part of a research experiment and that the written narratives would not be considered as part of their course grades. During the first session, the participants performed here-and-now $(\mathrm{HN})$ task. They were given a picture story and a prompt that had been written in present tense. They also received a piece of paper to write their narratives. They were allowed to view the picture story while writing. During the second session, they performed there-and-then (TT) task. All participants received a picture story and a prompt that had been written in past tense. Then, they viewed their picture story for 5 minutes and after that the picture stories were removed. Next, receiving a piece of paper, each participant started writing the narrative. Subsequently, the written narratives were collected and evaluated in terms of accuracy, fluency, and complexity based on previously mentioned production measures. Finally, matched t-test, for statistical analysis, was employed.

\section{Results}

Table 2 provides the descriptive statistics for accuracy, fluency, and complexity of L2 learners' written narratives in here-and-now (HN) task versus there-and-then (TT) task.

\section{Insert Table 2 Here}

As can be seen, the mean of accuracy in TT task $(\bar{X}=0.5048)$ is greater than that $(\bar{X}=0.4896)$ in HN task. Moreover, the mean of fluency in TT task $(\bar{X}=8.7750)$ is greater than the mean of fluency in HN task $(\bar{X}=7.4340)$. The mean of complexity in TT task $(\bar{X}=1.6252)$, in addition, is greater than the mean of complexity in HN task ( $\bar{X}=1.5908)$.

Table 3 displays the results of matched t-tests for accuracy, fluency, and complexity of L2 learners' written narratives in here-and-now (HN) task versus there-and-then (TT) task.

\section{Insert Table 3 Here}

As the table illustrates, since the significance level of matched t-tests in case of accuracy and complexity of written narratives are higher than 0.05 (significance level $\mathrm{p}<.05$ ), increasing task complexity had no significant effect on accuracy and also complexity of written narratives. However, the result of matched t-test shows that there is statistically significant difference between the fluency of written narratives in HN task and TT task. The significance level of matched t-test, regarding fluency, equals 0.000 and this values is lower than 0.05 (significance level $\mathrm{p}<.05$ ). It means that only fluency of written narratives was influenced by increasing cognitive complexity of the task. Therefore, our research hypothesis stating that "increasing task complexity has significant effect on L2 learners' written performance regarding accuracy, fluency, and complexity" is confirmed in terms of fluency. Conversely, the research hypothesis is not confirmed in terms of accuracy and complexity.

Figure 1 illustrates the mean of accuracy of L2 learners' written narratives in here-and now task versus there-and-then task. As mentioned before, the mean of accuracy in there-and-then task (0.5048) is greater than the mean of accuracy in here-and-now task (0.4896), though it is not statistically confirmed.

Insert Figure 1 Here 
Figure 2 shows the mean of fluency of L2 learners' written narratives in here-and-now task versus there-and-then task. As the figure demonstrates, the mean of fluency in there-and-then task is greater than that in here-and-now task and this difference is statistically significant.

Insert Figure 2 Here

Figure 3 illustrates the mean of complexity of L2 learners' written narratives in here-and-now task versus there-and-then task. Although the mean of complexity in there-and-then task is greater than the mean of complexity in here-and-now task, this difference is not statistically significant based on the result of matched t-test.

Insert Figure 3 Here

\section{Discussion}

The results of the study revealed that accuracy and also complexity of L2 learners' written task performance were not affected significantly by increased task complexity. Data analysis of the study also showed that there was statistically significant effect of task complexity on fluency of L2 learners' written task performance. In other words, we found a beneficial effect of increasing task complexity only on fluency of written task performance.

The results of this study are in line with Skehan \& Foster's (2001, p.193) proposition that "prioritization or predisposition (or both) seem to orient performance towards one (or two) of the three areas [accuracy, fluency, and complexity] theorized to be important, with the result that the other(s) suffers."

The obtained result is also in line with VanPatten's (1990) proposition that when learners are free to allocate attention, they prioritize give attention to the content over concern for the form.

\section{Conclusion}

The findings of the study demonstrate that there is statistically significant effect of task complexity only on fluency of L2 learners' written narratives. In other words, task complexity has no significant effect on accuracy and complexity of L2 learners' written narratives. It means that the results of the study are in line with Skehan \& Foster's Limited Attentional Capacity Model (Skehan, 1998; Skehan \& Foster, 1999, 2001). According to Skehan \& Foster (2001), increasing task complexity reduces learners' attention capacity; consequently, they will prioritize concern for one aspect of performance (accuracy, fluency, complexity) and this prioritization will hinder improvement in the other areas.

\section{Implications}

The present study provides insights on designing and implementation of tasks in L2 classroom settings. As Robinson (2003) argues the major problem in task-based language teaching is determining criteria for grading and sequencing tasks; therefore, data based empirical research is needed to determine the criteria affecting task difficulty. In line with this suggestion, the findings of this study can be used as an empirical basis for selecting, grading, and sequencing tasks. Meanwhile the findings of this study will also have practical implications in syllabus design, testing and SLA research.

\section{References}

Arent, R. (2003). Promoting revision and development in L2 writing through a combination-based curriculum. The Korea TESOL Journal, 6(1), 1-26.

Brown, G. \& Yule, G. (1983). Teaching the spoken language: an approach based on the analysis of conversational English. Cambridge: Cambridge University Press.

Foster, P. \& Skehan, P. (1999). The influence of source of planning and focus of planning on task-based performance. Language Teaching Research, 3(3), 215-247.

Gilabert, R. (2004). Task complexity and L2 narrative oral production. Unpublished Ph.D. dissertation. University of Barcelona, Spain.

Gilabert, R. (2007). Effects of manipulating task complexity on self-repairs during L2 oral production. International Review of Applied Linguistics, 45, 215-240.

Ishikawa, T. (2006). The effects of task complexity and language proficiency on task-based language performance. The Journal of Asia TEFL, 3(4), 193-225.

Ishikawa, T. (2008). The effects of task demands of intentional reasoning on L2 speech performance. The Journal of Asia TEFL, 5(1), 29-63. 
Kim, Y. (2009). The effects of task complexity on learner-learner interaction. System, 37, 254-268.

Kuiken, F., \& Vedder, I. (2007). Task complexity and measures of linguistic performance in L2 writing. International Review of Applied Linguistics, 45(3), 261-284.

Kuiken, F., \& Vedder, I. (2008). Cognitive task complexity and written output in Italian and French as a foreign language. Journal of Second Language Writing, 17, 48-60.

Ortega, L. (1999). Planning and focus on form in L2 oral performance. Studies in Second Language Acquisition, 21, 109-148.

Rahimpour, M. (1997). Task complexity, task condition, and variation in L2 oral discourse. Unpublished Ph.D. thesis, University of Queensland, Australia.

Rahimpour, M. (1999). Task complexity and variation in interlanguage. In N. O. Jungheim \& P. Robinson (Eds.), Pragmatic and pedagogy: proceeding of the $3^{\text {rd }}$ pacific Second Language Research Forum (pp.115-134). Tokyo, Japan: Pac LRF.

Rahimpour, M. (2007). Task complexity and variation in L2 learners' oral discourse. Working Papers in Language and Linguistics, University of Queensland, 1-9.

Robinson, P. (1995). Task complexity and second language narrative discourse. Language Learning, 45(1), 99-140.

Robinson, P. (2001). Task complexity, task difficulty, and task production: exploring interactions in a componential framework. Applied Linguistics, 22(1), 27-57.

Robinson, P. (2003). The cognition hypothesis, task design, and adult task-based language learning. Second Language Studies, 21(2), 45-105.

Robinson, P. (2005). Cognitive complexity and task sequencing: studies in a componential framework for second language task design. International Review of Applied Linguistics, 43, 1-32.

Robinson, P. (2007). Task complexity, theory of mind, and intentional reasoning: effects on L2 speech production, interaction, uptake and perceptions of task difficulty. International Review of Applied Linguistics, 45(3), 193-213.

Robinson, P. \& Gilabert, R. (2007). Task complexity, the cognition hypothesis and second language learning and performance. International Review of Applied Linguistics, 45(3), 161-176.

Skehan, P. (1996). A framework for the implementation of task-based instruction. Applied Linguistics, 17(1), 38-62.

Skehan, P. (1998). A cognitive approach to language learning. Oxford: Oxford University Press.

Skehan, P. \& Foster, P. (1999). The influence of task structure and processing conditions on narrative retellings. Language Learning, 49(1), 93-120.

Skehan, P. \& Foster, P. (2001). Cognition and tasks. In P. Robinson (Ed.), Cognition and second language instruction (pp.183-205). Cambridge: Cambridge University Press.

Storch, N. (2009). The impact of studying in a second language (L2) medium university on the development of L2 writing. Journal of Second Language Writing, 18, 103-118.

VanPatten, B. (1990). Attending to content and form in the input: an experiment in consciousness. Studies in Second Language Acquisition, 12, 287-301.

Williams, M., \& Burden, R. L. (1997). Psychology for language teachers: a social constructivist approach. Cambridge: Cambridge University Press.

Yuan, F., \& Ellis, R. (2003). The effects of pre-task planning and on-line planning on fluency, complexity and accuracy in L2 monolgic oral production. Applied Linguistics, 24 (1), 1-27.

Yule, G. (1997). Referential communication tasks. Hillsdale, NJ: Erlbaum. 


\section{Appendix A. Picture Story 1 (Here-and-Now Task)}

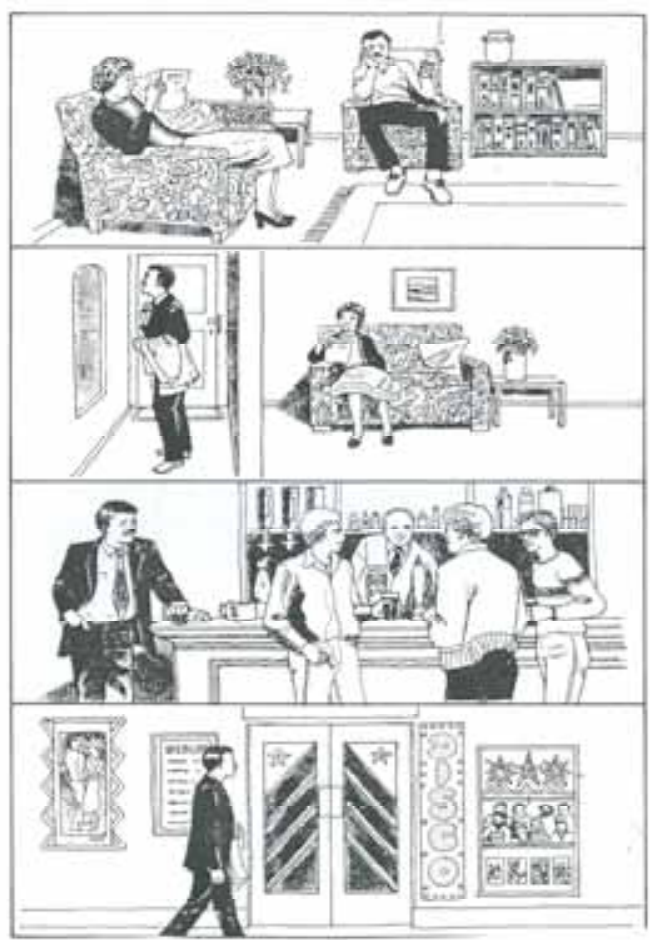

From Teaching the Spoken Language (Brown \& Yule, 1983)

Appendix B: Picture Story 2 (There-and-Then Task)
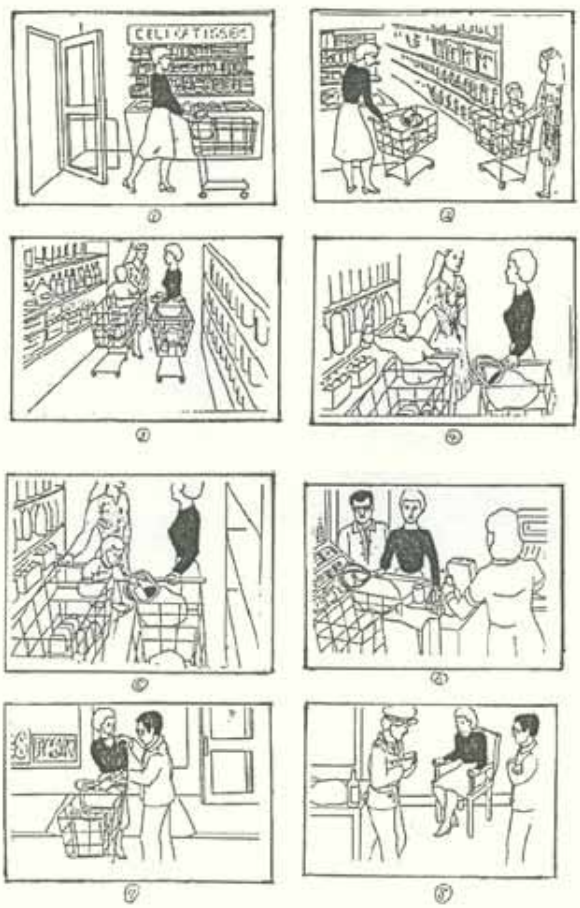

From Referential Communication Tasks (Yule, 1997) 
Table 1. A triad of task complexity, task conditions and task difficulty factors (Robinson, 2005, p.5)

\begin{tabular}{|c|c|c|}
\hline $\begin{array}{c}\text { Task Complexity } \\
\text { (cognitive factors) }\end{array}$ & $\begin{array}{c}\text { Task Conditions } \\
\text { (interactional factors) }\end{array}$ & $\begin{array}{c}\text { Task Difficulty } \\
\text { (learners factors) }\end{array}$ \\
\hline (a) resource-directing & (a) participation variables & (a) affective variables \\
e.g., \pm few elements & e.g., open/closed & motivation \\
\pm Here-and-Now & one-way/two-way & anxiety \\
convergent/divergent & \\
\pm no reasoning demands & confidence \\
& (b) participant variables e.g., & (b) ability variables \\
(b) resource-dispersing & same/different gender & e.g., working memory \\
e.g., \pm planning & familiar/unfamiliar & intelligence \\
\pm single task & power/solidarity & aptitude \\
\hline prior knowledge & &
\end{tabular}

Table 2. Descriptive statistics for learners' written narratives

\begin{tabular}{|c|c|c|c|}
\hline & Mean & $\mathrm{N}$ & Std. Deviation \\
\hline Accuracy HN & .4896 & 52 & .20253 \\
\hline Accuracy TT & .5048 & 52 & .24291 \\
\hline Fluency HN & 7.4340 & 52 & 1.58227 \\
\hline Fluency TT & 8.7750 & 52 & 2.04883 \\
\hline Complexity HN & 1.5908 & 52 & .32923 \\
\hline Complexity TT & 1.6252 & 52 & .38096 \\
\hline
\end{tabular}

Table 3. Matched t-tests for accuracy, fluency, and complexity of learners' written narratives

\begin{tabular}{|c|c|c|c|c|c|}
\hline & \multicolumn{2}{|c|}{ Paired Differences } & \multirow{2}{*}{$\begin{array}{c}\text { Observed } \\
t\end{array}$} & df & \multirow{2}{*}{ Sig. (2-tailed) } \\
\cline { 2 - 3 } & Mean & Std. Deviation & -.427 & 51 & .671 \\
\hline $\begin{array}{c}\text { Accuracy HN } \\
\text { \& Accuracy TT }\end{array}$ & -.01519 & .25681 & -4.682 & 51 & .000 \\
\hline $\begin{array}{c}\text { Fluency HN } \\
\text { \& Fluency TT }\end{array}$ & -1.34096 & 2.06532 & -.567 & 51 & .573 \\
\hline $\begin{array}{c}\text { Complexity HN } \\
\text { \& Complexity TT }\end{array}$ & -.03442 & .43753 & 573 \\
\hline
\end{tabular}

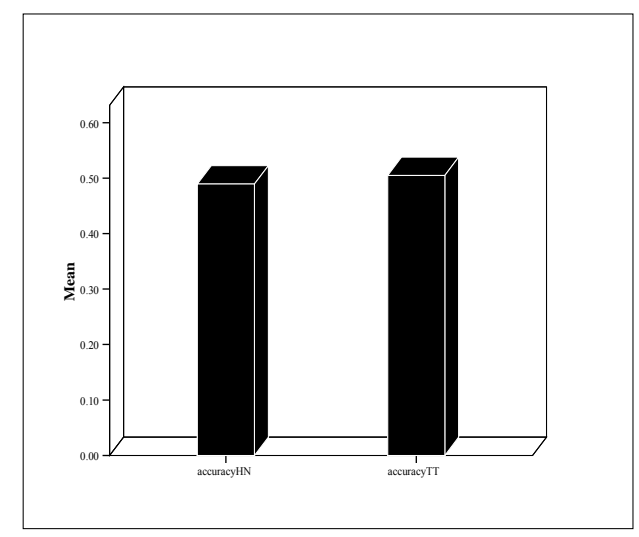

Figure 1. Mean of accuracy of L2 learners' written narratives in HN task vs. TT task 


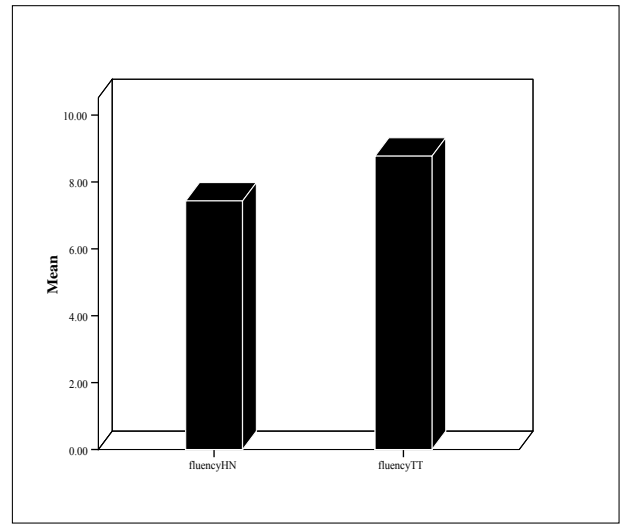

Figure 2. Mean of fluency of L2 learners' written narratives in HN task vs. TT task

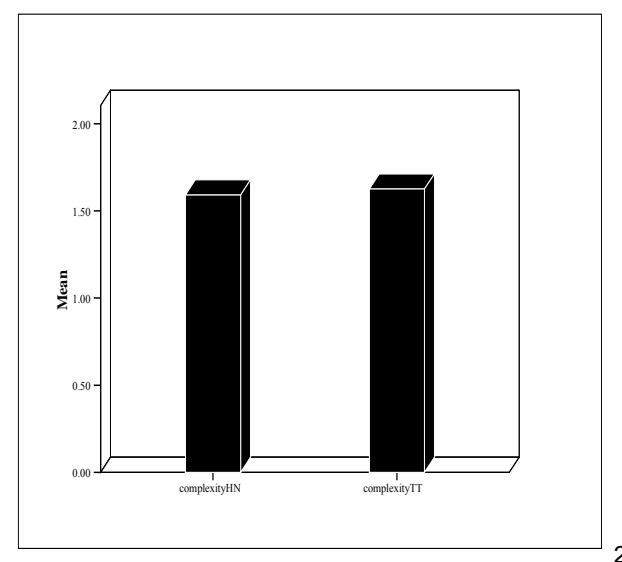

Figure 3. Mean of complexity of L2 learners' written narratives in HN task vs. TT task 